\title{
Translators' Subjectivity on the Lexical Level under the Pragmatic Adaptation Theory- A Case Study of the English Version of Fortress Besieged
}

\author{
Chao Zhang \\ School of Foreign Languages, Qingdao University of Science and Technology, China
}

\begin{abstract}
Traditional translation studies are source-text oriented, which usually ignore the study on translators and thereby make translators' status marginalized; however, the "cultural turn" in the 1970s in translation studies expands the space of translation studies and makes translators' subjectivity a hot topic. In this paper, the Pragmatic Adaptation Theory, proposed by Jef. Verschueren in his famous monograph Understanding Pragmatics is applied to the analysis of translators' subjectivity. According to the theory, using language must consist of the continuous making of linguistic choices consciously or unconsciously, for language-internal and/or external reasons. As an actual language use, translation practice is also entangled with translators' subjective choice-makings, both in form and in strategy. This paper offers the definition of translators' subjectivity under the Pragmatic Adaptation Theory and selects Kelly \& Mao's English version Fortress Besieged to study the manifestation of the translators' subjectivity in it from the lexical level. It is found that in their intentional choice-making process of translation, the translators of Fortress Besieged give full play to their subjectivity to make the target text adapt to the linguistic and cultural contexts of the target language. After the analysis on the lexical level, this paper concludes that the Pragmatic Adaptation Theory has powerful explanatory competence on the translators' subjectivity displayed in the English version of Fortress Besieged and the so-called unfaithfulness in the target text is the result of the translators' incessant adaptive choice-makings to achieve the translation purpose and the communicative effect of the target text.
\end{abstract}

Index Terms - translators' subjectivity, the Pragmatic Adaptation Theory, the lexical level, Fortress Besieged

\section{INTRODUCTION}

Traditional translation studies are source-text oriented, which usually ignore the study on translators and thereby make translators' status marginalized; however, the "cultural turn" in the 1970s in translation studies expands the space of translation studies and makes translators' subjectivity a hot topic.

Among a variety of linguistic approaches which have been employed in the analysis of translation, the Pragmatic Adaptation Theory, proposed by Verschueren, provides a new perspective. Verschueren (2005) assumes that language use is a continuous making of linguistic choices with different degrees of salience for the purpose of adaptation. Translation, as a kind of language use, is no exception. Translators, first as readers, understand original texts through their languages; then as mediators, transfer source texts through their adaptation to their target languages. The whole translation process involves translators' incessant adaptive choice-makings in language form and content as well as in translation strategies.

On the subject of translation, many scholars in translation study field have written articles but have not reached a consensus. Generally there are four viewpoints: (1) the translator (2) the author and the translator (3) the translator and the readers (4) the author, the translator and the reader (Xu Jun, 2003). Although they seem to be confusing, all of these four opinions are supported by the developing philosophy and literary theories. Under the guidance of different theories, scholars form different viewpoints on the subject-object relation, the text-translator relation, and the author-translator-reader relation.

French scholar Antoine Berman states that both in translation criticism study and in its practical performance, people have to take translators as the subject, which ought to be considered a fundamental proposition (Xu Jun, 2003).

Yang Wuneng (1987) thinks that the subject of literary translation is the author, the translator and the reader. He holds that the source text and the target text are merely tools or carriers through which the translator and the author communicate with each other; however, in translation process, the translator occupies the center, performing all of the active work. In Yang' viewpoint, target text is a product made by the cooperative efforts of the author, the translator and the reader.

Xu Jun (2003) points out that studies on translation subject develop from the traditional author-centered model to the active conversations among the author, the translator and the reader. In the latter model, the translator becomes the core of this conversation and functions most actively in contrast to the author and the reader who are also regarded as the subject of translation activity. Actually, Xu classifies the subject of translation in two categories: the broad sense and the narrow sense. In the broad sense, the author, the translator and the reader are looked upon as the translation subject; 
whereas, in the narrow sense, the translation subject refers merely to the translator.

Based on various definitions of translation, Zha Mingjian \& Tian Yu (2003) put forward their understanding of translation subject. If translation refers to the process of translation, translation subject should refer to the translator. The original text, the author and the reader therefore are the objects which the translator's practical activity aims at. In this sense, the original text becomes the object for the translator to understand, interpret while the author an assistant who helps the translator to complete the translation activity, and the reader the direction which the translation practice points to. If the concept of translation involves not only the translation activity, but also all of the relevant factors that affect translation activity, then the author and the reader should be counted in as part of translation subject.

From the above discussion on translation subject, it can be seen that the translator is always considered the most crucial and active element in translation activity, while the author and the reader only appear in some related links of translation process. This thesis focuses merely on the initiative and creative role that translators play in translation process; thereby, the subject of translation herein refers to translators and the subjectivity of translation is confined to translators' subjectivity.

Fortress Besieged written by Mr. Ch'ien Chung-shu was translated into English by Jeanne Kelly and Nathan K. Mao. The English version achieved great success and was regarded as "the most outstanding academic works" by the American Books Association from 1980 to 1981. However, this English version also encounters such criticism both at home and abroad as mistranslation, impure English, the abuse of American slang and idioms, and rigid cultural transplantation, etc. Most of the criticism is discussed from the angle of the traditional translation outlook, ignoring the translators' subjectivity in the translation process. This paper carries out a tentative research on one part of translators' subjectivity in Fortress Besieged from the angle of the Pragmatic Adaptation Theory on the lexical level, aiming to prove that the translator's subjectivity displayed in Fortress Besieged can be adequately explained by the Pragmatic Adaptation Theory.

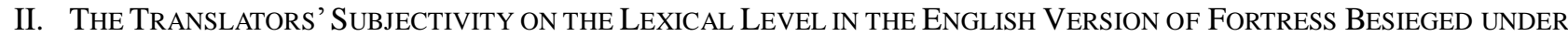 THE PRAGMATIC ADAPTATION THEORY}

\section{A. Translators'Subjectivity}

Translators are the only subject in translation process, so the quality of the final translation totally depends upon their ability of understanding and choice-making. In order to successfully transfer the meanings of original texts without bringing about understanding obstacles for their expected readers, translators, as the central figures in translation process, have to take into account the linguistic and cultural context of the target language, and make flexible adaptations where it is necessary. Only in this way can they improve the readability and acceptability of the target text and in the meantime achieve their translation purposes. So translators' subjectivity under the Pragmatic Adaptation Theory is defined as "translators' manipulating force which guides them to make continuous adaptive linguistic choices, both consciously and unconsciously, during translation process in order to achieve their intended translation purposes". The manipulating force mainly refers to the initiative and creativity that are manifested by translators in their adaptive choice-makings while translating. In other words, in translation process, translators' subjectivity is mainly displayed in their adaptive understanding of the source text and the dynamic adaptive choice-making of language forms and translation strategies. In this sense, we can say the Pragmatic Adaptation Theory is explicative for translators' subjectivity.

The choice-makings may occur at different structural levels of language, but this paper focuses on its lexical level in Fortress Besieged, which can best manifest the translator's subjectivity.

\section{B. The Translators'Subjectivity on Lexical Level}

The analysis of the manifestation of the translators' subjectivity on Lexical Level in Fortress Besieged will be presented from the following angles: addition, omission, substitution, shift of perspective.

\section{a. Addition}

The translators in the translation process of Fortress Besieged make this linguistic choice by adding information to the original text to make the target text more adaptive to the reception context so as to achieve the intended purpose.

Example 1

ST: 诗人听了, 欢喜得圆如太极的肥脸上泛出黄油。

(Ch'ien, 2002, p.77)

TT: Upon hearing this, the poet was so delighted that his plum face, as round as the T'ai-chi diagram.

(Kelly \& Mao, 2003, p.239)

In this example, “太极” was translated into “T'ai-chi diagram”. If it is translated literally into “T'ai-chi”, western readers would feel rather confused, for many westerners will mistake T'ai-chi for one of the most popular martial arts in China. So the translators make the choice of addition to render the source text to help the target readers catch the real meaning of “太极” herein.

Example 2

ST: 总而言之, 批分数该雪中送炭, 万万不能悭吝。 
(Ch'ien, 2002, p.242)

TT: One should "send coal when it snows", that is, provide that which is most needed, and never be stingy.

(Kelly \& Mao, 2003, p.224)

In this example, to make “雪中送炭” more understandable, the translators add an explanation to its literal translation.

Example 3

ST: 只可惜把太阳旗误认为真的太阳。

(Ch'ien, 2002, p.339)

TT: The only trouble being that it mistook the sun flag (of Japan) for the real sun.

(Kelly \&Mao, 2003, p.315)

In the target text of Example 8 two words "(of Japan)" is added to "the sun flag". With the added information, westerners need not bother to make guesswork at what the sun flag stands for and thereby are enabled to catch easily the meaning implied in the source text.

After the analysis of the three examples, it can be concluded that by adopting addition, the translators make the target text more understandable and acceptable, so that the target text can realize their communicative function. That is to say, it is just due to the employment of addition that the translators make the target text more adaptive to the cognitive world of western readers.

\section{b. Omission}

This linguistic choice made by the translators when they reckon that the omission of some words does not impair the western readers' comprehension of the target text.

Example 4

ST: 太太不忠实, 偷人, 丈夫做了乌龟, 买彩票准中头奖, 奢钱准赢。

(Ch'ien, 2002, p.5)

TT: Mr. Fang said that if the wife is unfaithful and has an affair, the husband is sure to take first prize if he buys a lottery ticket, and he is sure to win if he gambles.

(Kelly\& Mao, 2003, p.6)

Example 5

$\mathrm{ST}$ : 同事们相信他的吹牛。

(Ch'ien, 2002, p.247)

TT: His colleagues believed him anyway.

(Kelly \& Mao, 2003, p.229)

In Example 4, “做了乌龟” in the source text is omitted in the target text, since its meaning can be implied from the context of the sentence, the translators do not bother to translate it. In Example 10, “吹牛” in ST is omitted in TT for the same reason. From the analysis of these two examples, it can be concluded that the translators sometimes resort to omission to make the target text more concise and acceptable to its readers, provided that the adoption of omission does not bring about obstacles among western readers in their reading process. By so doing, the translators avoid redundancy and thus improve the acceptability of the target text.

\section{c. Substitution}

Because of the great differences between the Chinese readers and the westerners in culture, language, society and so on, some images and concepts in Fortress Besieged are beyond the westerners' encyclopedic information; thereby, the translators choose the technique, substitution to cope with this problem so that they make their linguistic choices adapt to the linguistic or communicative context of the target text.

Example 6

ST：正懒在床上胡想，鲍小姐外面弹舱壁，骂他“懒虫”，叫他快起来，同上岸去玩。

(Ch'ien, 2002, p.17)

TT: Just as he was loafing in bed, thinking of that nonsense, Miss Pao tapped on the outside of his cabin, called him "lazybones", and told him to hurry and get up so they could go ashore and have fun.

(Kelly and Mao, 2003, p.19)

Example 7

ST: 李梅亭拍手说: “这真是天罚他, 瞧这混蛋还要撒野不撒野。这旅馆里的饭不必请教了, 他们俩已经替咱 们做了试验品。”

(Ch'ien, 2002, p. 186)

TT: Li Mei-t'ing clapped his hands and said, “It must be heaven's punishment. Now we'll see whether that rascal gets out of hand again. We don't need to try the food in this hotel any more. Those two have already acted as guinea pigs for us."

(Kelly \& Mao, 2003, p.173)

Example 8

ST: 明早夫妻间还是鸦雀无声。

(Ch'ien, 2002, p.368)

TT: The next morning husband and wife continued to maintain a stony silence. 
(Kelly \& Mao, 2003, p.343)

Example 9

$\mathrm{ST}$ : 你把针在面上转一圈, 听见东一个电台半句京戏, 西一个电台一句报告, 忽然又是半句外国歌啦, 半句 昆曲啦, 鸡零狗碎, 凑在一起, 莫名其妙。

(Ch'ien, 2002, p.323)

TT: You give the dial a turn and catch a phrase of Peking opera from this radio station, a phrase of an announcement from that one, and then suddenly a phrase of a foreign song, a melody--- bits and pieces which make no sense when all brought together.

(Kelly \& Mao, 2003, p.299-300)

Example 10

ST: 切不可锦上添花, 让学生把分数看得太贱, 功课看得太容易。

(Ch'ien, 2002, p.242)

TT: Nor on the other hand should one gild the lily, letting the students regard grades as too cheap or their schoolwork as too easy.

(Kelly \& Mao, 2003, p.224)

The above examples exemplify the employment of substitution in the translation process of Fortress Besieged. The underlined Chinese words or set phrases do not have their complete equivalents in English, and the literal translation of them would undoubtedly puzzle the western reader. The translators thereby replace them with the functionally equivalent images. Although the original linguistic properties are not completely preserved, the westerners can still appreciate the same contextual effects as Chinese readers through translators' choice-makings of proper words and phrases in English. From this point of view, the translators' subjectivity embodied in the course of translation to adapt to the contextual correlates is decisive.

\section{$d$. Translators' Shift of Perspective}

Shift of perspective is a technique to work around the differences in languages, mediating between the source language and target language. In other words, by adopting the technique, the shift of perspective, the translators make a compromise between the two cultures concerned. The theoretical support lies in the fact that target language users differ to some degree from source language users in the ways of viewing the world, but they share some common understanding of the world. Sometimes translation problems can be resolved immediately if translators change their perspectives or express the same idea in another way.

Example 11

ST: (鸿渐) 忙将本电报明码翻出来是: “敬聘为教捋月薪三百四十元酌送路费盼电霸国立三闾大学校长高松 年”。“教捋”即 “教授” 的错误, “电霸” 准是 “电复”。

(Ch'ien, 2002, p.109)

TT: He quickly got a telegraph code book and transcribed it as follows: "Offer position as possessor. Monthly salary \$340 plus travel expenses. Please ware reply. National San Lü University President Kao Sung-nien.” "Possessor" was a mistake for "professor" and "ware reply" must be "wire reply".

(Kelly \& Mao, 2003, p.100)

In this example, the similarity between “电复” and “电霸” is substituted by the similarity between "wire reply” and "ware reply"; the similarity between “教授” and “教捋” is substituted by the similarity between "professor" and "possessor". From this example, we can see the translators make full use of their initiative and creativity to make the target text more adaptive to the mental world of the target readers and thereby realize the communicative function of the English version. The following is another example:

Example 12

ST: 鸿渐道: “我忘掉问你，你信上叫我“同情兄”，那是什么意思?”辛楣笑道: “这是董斜川想出来的。他 说同跟一个先生念书的叫“同师兄弟’，同在一个学校的叫“同学”，同有一个情人的该叫“同情””。

(Ch'ien, 2002, p.134)

TT: "I forgot to ask you. In your letter, you called me 'lovemate'. What do you mean by that?" Hsin-mei said with a grin, "That's something Tung Hsien-ch'uan thought up. He says people who study under the same teacher are called classmates, and people who go to the same school are called schoolmates, so people who are in love with the same girl should be called 'lovemates'.

(Kelly \& Mao, 2003, p.123-124)

In this example, the writer creates “同情” by imitating “同学”, and the translators correspondingly create a nonce word “lovemate” to render the nonce-word “同情”(同有情人) in the original. “-mate” is a commonly used suffix to form compounds which means person participating in the same activity, organization, or sharing the same accommodation. The English rule of word-formation permits the suffixation of -mate to a noun, to convey the meaning "belongs to the same organization", as in "classmate" and "roommate". However, this suffix cannot be added after "love" to mean "have the same lover" according to conventions. The nonce-word "lovemate" enables the target text readers to appreciate the humor in the same way as the source text readers do.

Example 13 
ST: 偏偏结婚的那个星期三，天气是秋老虎，热得厉害。我在路上就想，侥天之幸，今天不是我做新郎。 (Ch'ien, 2002, p.149)

TT: Well, the Wednesday of their wedding turned out to be an "autumn tiger", a real scorcher. On the way there I thought, thank God, I'm not the bridegroom today.

(Kelly \& Mao, 2003, p.136)

In this example, the translators translated “侥天之幸” into “thank God" rather than “thank heaven” in order to adapt to the mental world of the western readers. Because influenced by Christianity the majority of westerners believe in God while Chinese believe in heaven mainly for the impact of Confucianism, Taoism and Buddhism.

In Examples 11-13, the shift of perspective is adopted in the translation process. The target text seems to be competing with the source text due to the translators' subjectivity fully played in the English version. Through the choice-making of this technique, shift of perspective, the translators have enhanced the readability of the target text so that the target text readers can experience the same enjoyment in reading as the source text readers.

\section{CONCLUSION}

This paper makes a tentative probe into the manifestation of the translators' subjectivity on the lexical level in Fortress Besieged under the guidance of the Pragmatic Adaptation Theory. Based on Verschueren's Pragmatic Adaptation Theory and the qualitative analysis of translators' subjectivity, along with the empirical case study of Fortress Besieged concerning the manifestation of the translators' subjectivity in it on the lexical level, the author arrives at the following conclusions:

Firstly, the Pragmatic Adaptation Theory, with which Verschueren intends to give a general exploration on language use, has powerful explanatory competence on the study of translation process and translators' shift of perspective. It can help us to analyze translators' choice-making process and find out the factors that influence their decisions.

Secondly, in translation process, translators usually give full play to their initiative and creativity to make their specific linguistic choices to adapt to specific contextual correlates on different structural levels at high level of salience to reach the points of satisfaction and the communicative needs. So it is safe to say the synthesizing of the study of translators' subjectivity with the Pragmatic Adaptation Theory justifies the translators' subjectivity in the translation process of Fortress Besieged.

Thirdly, through the analysis of the examples taken from Fortress Besieged from the Pragmatic Adaptation Theory, it can be seen that the translators' performance needs to be reconfirmed, for most of the translation problems concerning "unfaithfulness" are the result of the translators' intentional choice-makings to adapt to the linguistic and communicative contexts of the target text. In this sense, the so-called unfaithfulness caused by linguistic or cultural adaptations can not be avoided. After all, whether we admit it or not, translators will never escape the influence of their own language and culture. Objectively speaking, the nature of translation determines that no translation would be perfect without any inadequacy, just as Gentzler said "no translation is entirely adequate to the original version, because the cultural norms cause shifts from the source text structures" (Gentzler, 2004: 126). The translators, therefore, should not be excessively demanded and their names are to be rectified.

\section{REFERENCES}

[1] Ch'ien Chung-shu. (2002). Fortress Besieged. Beijing: SDX Joint Publishing Company.

[2] Ch'ien Chung-shu. (2002). Fortress Besieged. Translated by Jeanne Kelly \& Nathan K. Mao. (2003). Fortress Besieged. Beijing: Foreign Language Teaching and Research Press.

[3] Dennis, Hu. (1978). A Linguistic-literary of Ch'ien Chung-shu's Three Creative Works. The Journal of Asian Studies, (3): 427-443.

[4] Gentzler, Edwin. (2004). Contemporary Translation Theories (revised $2^{\text {nd }}$ edition). Shanghai: Shanghai Foreign Language Education Press.

[5] Hatim, B \& I. Mason. (1997). The Translator as Communicator. London/New York: Routledge.

[6] Hu Gengshen. (2004). The Approach to Translation as Adaptation and Selection. Wuhan: Hubei Education Press.

[7] Verschueren, Jef. (2005). Understanding Pragmatics. Beijing: Foreign Language Teaching and Research Press.

[8] Wilss, W. (2001). The Science of Translation-Problems and Methods. Shanghai: Shanghai Foreign Language Education Press.

[9] Xu Jun. (2003).Creative Treason and the Translators' Subjectivity. Chinese Translators Journal, (1): 6-11.

[10] Yang Wuneng. (1987). A Cycle of Interpretation,Acceptance and Creation. Chinese Translators Journal, (6): 3-6.

[11] Zha MingJian \& Tian Yu. (2003). On the Subjectivity of the Translator. Chinese Translators Journal, (1):19-24.

Chao Zhang was born in Linyi, China in 1975. She received her M.A. degree in linguistics from Qingdao University of Science and Technology, China in 2008.

She is currently an associate professor in Foreign Languages School, Qingdao University of Science and Technology, Qingdao, China. Her research interests include teaching methodology and translation theories and practice.

Ms. Zhang is a member of Translation Institution of Qingdao University of Science and Technology. 